leave it until after graduation (as sometimes suggested) is too late.

It is worth considering whether courses in 'ongineering science' should form part of every undergraduate science syllabus. Such courses (if well taught) might servo to light a spark of positive interest in the applications of scionce and to mitigate the excessively genteel attitude of graduate scientists towards technology. At the same time much-increased opportunities and encouragement might be provided for changing ovor from science to technology in the course of a university career; this might come to be regarded as a normal route into technological studies. The problem of channelling talent into technology would thereby be partly removed from the schools to the universities, where the case for technology can be properly put and the student may be expected to take a more mature and realistic viow.

However, both pure science departments and technological dopartments might find difficulties associated with changes of the kind suggested. Indeed, radical changes of any kind aro for many reasons difficult to introduce into established universities. Perhaps there is an opportunity here for the new univorsities to give tho rest of us a lead by breaking down the barriors between science and technology. This seems to offer the best chance of balaneing our scientific oconomy and restoring the status of the technologist to a healthy level.

'Technology and the Sixth Form Boy, Oxf. Univ. Dep. Education, 1963. See also Nature, 199,958 (1963).

Assoc. Sci. Educ., 52 Bateman Street, Cambridge, 1963.

s Education, 1045 (May 24, 1963).

\title{
RADIO STAR AND SATELLITE SCINTILLATIONS
}

$\mathrm{D}^{\mathrm{D} t h}$ URING August 19-20 a conference was held at the Physics Department of the Univorsity of Adelaide on the subject of "Radio Star and Satellite Scintillations". The conforence was held under the auspices of the Austra. lian Institute of Physics (South Australian Division).

The conference opened with a survey by Dr. B. H. Briggs (University of Adelaide), who showed how irregularitios in the ionosphere could be detected by various methods, all concerned with effects on radio waves. In the caso of the $F^{\prime}$ region, these methods include radio star scintillations, fluctuations of radio waves received from satellites, spread echoes observed in ionosphere soundings (spread- $F^{\prime}$ ), and radar back-scatter using froquencies around $20 \mathrm{Mc} / \mathrm{s}$. These phenomena are found to be correlated, which suggests that they are all due to the samo irregularities in the ionization of the $F$ region. There is good evidence that the irregularitios are elongated, and 'fiold aligned', so that their longer dimension lies along the direction of the Earth's magnetic field. They occur at hoights from $200 \mathrm{~km}$ upwards; recent 'topside soundings' by tho Alouette satellito (Nature, 197, 636; 1963) show that on some occasions they exist at heights up to at least $1,000 \mathrm{~km}$.

When radio stars are observed at low angles of elevation, irregularitics lower down, in the $E$ region, aro found to be important. This might be expected, since the increase in thickness along the line of sight is greater for a layer of irregularities at a low height than for a layer at a great height, so that irregularities low down become relatively moro important. Irregularities in the $E$ region and below can also bo detected by several other methods, including the fading of reflectod waves, observations of 'sporadic $E$ ' ochoes on ionograms, and the investigation of weak irrogularities below the $E$ region by the seattering of radio waves at oblique or vertical incidence. A remarkablo feature of the irregularities revealed by the latter technique is their tendency to occur in stratified layers with a vertical separation of $10 \mathrm{~km}$.

After discussing these experimontal observations, Dr. Briggs turned to the vexed question of the origin of the irrogularities. In the $E$ region and below it is generally agreed that the irregularities are due to irregular air motions, though the relative importance of turbulence, random wave motions, and vertical shears in the horizontal wind is still uncertain. Higher up, in the $F$ region, these motions are damped out due to the high kinematic viscosity, and other mechanisms must bo found. The irregularities in the $F$ region do, indeed, seem to be a separate phonomenon, as is shown by their large intensity (deviations of electron density of \pm 50 por cent are common) and their tendency to occur mainly at night. Two early theories, which accounted in a simple way for the occurrence at night, were the accretion theory and the atmospheric tail theory. In the former the irregularities were thought to be produced by material falling into the Sun by gravitational attraction, and intercepted by tho Earth. In the latter an atmospheric 'tail' was postulated, pointing away from the Sun and produced either by radiation pressure or the effect of the solar wind. Later theories have attributed the irregularities to hydromagnetic waves entoring the atmosphere, to particle streams associated with the Van Allen bolts or the aurora, to instability of an ionospheric layer moving vertically under the action of an eloctrodynamic drift, and to irregular eloctric fields produced lower down in the $E$ region. Dr. Briggs suggested that the observations should, where possible, be discussed in relation to these theories, in order to attompt to eliminate some of them.

Dr. J. W. Warwick (University of Colorado and High Altitudo Obsorvatory, Boulder, Colorado) then described observations of radio star scintillations obtained with a swept-frequency interferometor. These observations showed that amplitude scintillations had a similar form over the range 7-41 Mc/s. Also, fluctuations in position of the source could bo determined and these often showed systematic trends as a function of froquency. Dr. Warwick showed that these could bo explained by geometrical optics if a succession of 'lenses', focusing approximately at ground-level, were assumed to exist in the ionosphere. On some occasions the obsorvations could be explained in terms of a wave-like structure moving with a velocity of about $50 \mathrm{~m} / \mathrm{sec}$.

Miss E. M. Matthew (University of Queensland) described some observations of radar ochoes from ficldaligned irrogularities in the $F$ region made at Brisbane. The echoes were relatod to variations in the outer Van Allen belt and to various ionogram anomalies. The northward speed of patches of irrogularities could be observed, and a sudden increase of speed was interpreted as arising from some form of impact on tho magnetosphere.

Dr. G. G. Bowman (University of Queensland) described investigations of the occurrence of spread- $F$ ochoes at mid-latitude stations, and these seom to show that spread- $F$ is most prevalent when tho air density in the upper $F$ region is low. Dr. B. H. Briggs (University of Adelaide) described observations of radio star scintillations and spread- $F$ echoes made in England. At sunspot maximum the irregularities incroase in intonsity but occur mainly above tho lovel of maximum ionization of the $F$ region and do not, therefore, produce sproad- $F$ echoes on ionograms. Thus the opposite trends of scintillation occurrence and spread- $F$ occurrence with the solar cycle can bo reconciled. The results appear to conflict with the 'instability' theory of Dr. D. F. Martyn, according to which irregularities would form mainly on the underside of the $F$ region. 
Dr. J. D. Whitehead (University of Queensland) then gave a critical survey of the theories of formation of irregularities in the $F^{\prime}$ region. He pointed out that, for hydromagnetic waves, the percentage fluctuation of electron density is equal to the percentage fluctuation of magnetic field, and this appears to demand unreasonably large amplitudes for the waves. The instability theory was criticized on the grounds that the observed vertical motions of the $F$ region were not those required by the theory. Dr. Whitehead suggested that the irregularities were produced either by air movements associated with internal gravity waves, or by irregular electric fields, and the theories of formation of irregularities by these mechanisms were considered. Dr. Whitehead stressed the need for more detailed measurements of the sizes and shapes of the irregularities so that the predictions of the theories could be tested.

On the second day of the conference, satellite scintillations were discussed. Unlike a radio star, a satellite sweeps rapidly across the sky from horizon to horizon, and so the method is particularly valuable for examining the geographical distribution of irregularities, especially if observations from several stations are combined. Dr. G. H. Munro (Radio Research Board, Sydney) described observations of this type, in which transmissions on $20 \mathrm{Mc} / \mathrm{s}$ from the satellites Nora Alice $I$ and $I I$ were used. The results showed that irregularities tend to occur in patches which become more frequent, and larger, at higher latitudes. The patches appear to be elongated east-west and may stretch in this direction for 1,000 miles or more. From measurements of the times of onset of scintillations at spaced stations the heights of the patches may also be determined.

Mr. I. A. Parkin (University of Adelaide) discussed the theory of the diffraction process which links the irregularities in the ionosphere to the pattern of amplitude and phase which is observed over the ground. He considered both a source at infinity and at a finite distance. If detailed deductions about the sizes and shapes of the irregularities are to be made, it is necessary to use frequencies such that the fluctuation of phase across the emerging wavefront is less than one radian. It is then possible to relate the auto-correlation function of ampli- tude measured on the ground to the auto-correlation function of the irregular medium. Mr. Parkin also pointed out that at a given distance from the irregularities certain Fourier components should be absent in the amplitude pattern, and so measurements of the power spectrum of the pattern may enable the height of the irregularities to be determined. Some discussion of the relation between the diffraction approach and the method of geometrical optics followed Mr. Parkin's paper, and it was agreed that in principle the diffraction method is always valid, but in practice it is most useful when the phase deviation is small, while the method of geometrical optics is useful when the phase deviation is large.

Attention then turned to irregularities at lower heights. Dr. R. G. Roper (University of Adelaide) described measurements of winds and turbulence in the height range 70-110 km, and Dr. J. D. Whitehead (University of Queensland) discussed the formation of sporadic $E$ which, at temperate latitudes, he considered to be produced by vertical shears in the horizontal wind. However, the irregular wind shears described by Dr. Roper had the greatest magnitude at the equinoxes, and this does not agree with the occurrence of sporadic $E$, which is most prevalent in summer. Dr. Whitehead also discussed the formation of equatorial sporadic $E$, which he suggested was due to irregularities formed by sound waves.

The conference concluded with two papers of a more technical nature. Dr. L. H. Heisler (Radio Research Board, Sydney) described equipment for the investigation of the variation with frequency of the amplitude of radio waves reflected from the ionosphere, and Dr. J. D. Whitehead (University of Queensland) described a proposed method for measuring with increased precision the virtual height of reflexion.

During the conference the opportunity was taken to discuss observations of the forthcoming S66 Beacon satellite which are being planned in Australia and New Zealand. The general feeling was that much more work needs to be done before the mode of formation of ionospheric irregularities is properly understood, and that intensive observations using the Beacon satellite are likely to make a valuable contribution towards this end.

B. H. BrigGs

\section{OXIDATIVE PHOSPHORYLATION AND RELATED PROCESSES}

\section{$\mathrm{T}$} HE Medical Sciences Club of South Australia and the Australian Biochemical Society (South Australian Branch) held a symposium on "Oxidative Phosphorylation and Related Processes" in the Biochemistry Department, University of Adelaide, during June 14-15.

Prof. E. C. Slater (Amsterdam) opened the symposium with a review of present-day theories on the formation of adenosine triphosphate in mitochondria. He contrasted Mitchell's theory that this process is the reversal of hydrolysis of adenosine triphosphate by an anisotropic adenosine triphosphatase to the more widely accepted view that adenosine triphosphate is produced by reactions involving a number of specific intermediates formed at several different 'sites' in the sequence of oxidationreduction catalysts in mitochondria. Much of the evidence for such intermediates has been obtained in experiments with oligomycin, which prevents formation of adenosine triphosphate but does not inhibit other reactions such as the reduction of nicotinamide-adenine dinucleotide by succinate; for thermodynamic reasons, this reduction must be coupled to exergonic processes such as the decomposition of compounds like the proposed intermediates. However, these investigations do not allow a final choice between Mitchell's theory and that preferred by Slater, Chance and others involving specific intermediates of the type often formulated as $A \sim C$. It was pointed out in discussion that the existence of adenosine triphosphate and adenosine diphosphate in a region of the mitochondrion not accessible to oligomycin would invalidate certain conclusions drawn from experiments with this inhibitor.

Prof. J. S. Sturtevant (Yale) described kinetic investigations of the interaction of cytochrome $b_{2}$ (the $\mathrm{L}(+)$-lactate dehydrogenase of yeast) with lactate and ferricyanide. Using a stopped-flow spectrophotometer at a number of wave-lengths, evidence was obtained which indicated a preliminary reduction of flavin mononucleotide, an intra-molecular transfer of electrons to protohæm, and interaction of both prosthetic groups of this flavohæmoprotein with ferricyanide. The results support earlier suggestions by Morton, who found equimolar quantities of these prosthetic groups in the enzyme and proposed a mechanism involving intra-molecular transfer of electrons from flavin to hæm. The need to find if cytochrome $b_{2}$ is a constituent of yeast mitochondria was considered in the general discussion following these papers. Clearly a single flavohæmoprotein is a potential model for the more complex flavin-hæm systems of the whole mitochondrion.

Dr. M. R. Atkinson (Adelaide) reviewed recent evidence for phosphorylated and unphosphorylated intermediates of oxidative phosphorylation and described electrophoretic investigations (with urea-starch gels or on paper after 